\title{
Teste de aceitação e composição centesimal de carne de jacaré-do-papo-amarelo (Caiman latirostris) em conserva
}

\author{
Acceptance test and percent composition of broad-snouted caiman (Caiman latirostris) canned meat
}

\author{
Isabela Ciarlini de Azevedo ${ }^{\mathrm{I}}$ Renato Poubel do Carmo ${ }^{\mathrm{I}}$ Alexandre Guedes Torres ${ }^{\text {II }}$ \\ Eliane Teixeira Mársico ${ }^{\mathrm{III}}$ Mônica Queiroz de Freitas ${ }^{\mathrm{II}}$
}

\section{RESUMO}

O objetivo, neste trabalho, foi avaliarem-se três formulações de carne de jacaré-do-papo-amarelo (Caiman latirostris) em conserva: em óleo comestível, em salmoura com cebola e em salmoura temperada. Após o abate, foram separados cortes (seis pares de membros, uma cauda, duas costelas e dois lombos) para a fabricação das conservas. Antes do processamento industrial, realizou-se a análise de ácidos graxos da carne in natura através de cromatografia gasosa. Após o processo de enlatamento, procedeu-se o teste de esterilidade comercial para alimentos de baixa acidez para as conservas elaboradas, para então avaliar a aceitação sensorial das três formulações, utilizando escala hedônica estruturada de nove pontos. Foram avaliadas a aparência e a impressão global. Foram analisados também o teor de cloreto de sódio, o $\mathrm{pH}$ e a composição centesimal (umidade, resíduo mineral fixo, proteínas e lipídeos) das conservas. Os ácidos graxos saturados, monoinsaturados e poliinsaturados corresponderam, respectivamente, a 28,5; 42,5 e 29,0\% do total de ácidos graxos da carne in natura. As conservas, com ausência de vazamento ou estufamento no teste de esterilidade, foram liberadas para análise sensorial. Em relação à aparência, observou-se que as três amostras diferiram significativamente entre si, sendo a conserva em cebola a menos aceita, seguida da conserva temperada e em óleo, que foi a mais aceita. Em relação à impressão global, a conserva em óleo também foi a mais aceita. O teor de cloreto de sódio variou de 0,5 a 1,2\%, sendo mais elevado nas conservas em salmoura. A carne de jacaré-do-papo-amarelo em conserva apresentou um $\mathrm{pH}$ médio de 5,0, umidade de 76,0\%, resíduo mineral fixo de 1,3\%, concentração de proteínas de $12,4 \%$ e teor de lipídeos totais de 5,5\%. A conserva em óleo apresentou um teor de lipídeos mais elevado (12,8\%). De acordo com os resultados, pode-se concluir que a comercialização de carne de jacaré-do-papo- amarelo em conserva é viável, permitindo o melhor aproveitamento da carne após o abate, com aumento do seu valor agregado e uma boa aceitação sensorial do produto.

Palavras-chave: carne de jacaré, conserva, teste de aceitação, composição centesimal.

\section{ABSTRACT}

This research focused on the evaluation of three broad-snouted caiman (Caiman latirostris) canned meat formulas: one in edible oil, another in salt with onions, and the third one in seasoned salt. Some cuts (six pairs of members, one tail, two ribs and two loins) were separated after slaughter to produce the canned meat. Gas chromatographic analysis of the fatty acids in the non-processed meat was conducted before industrial processing. After the canning process, a commercial sterility test for low acidity food was conducted for the canned meat samples. Subsequently, the three formulations were tested for sensory acceptance by a 9-point hedonic scale with respect to their appearance and global impression. The sodium chloride content, $\mathrm{pH}$ and percent composition (moisture, fixed mineral residue, proteins and lipids contents) of the canned meat samples were determined. The saturated, monounsaturated and polyunsaturated fatty acids values were, respectively, 28.5; 42.5 and $29.0 \%$ of the total fatty acids in the non-processed meat. The canned meat samples were released after verifying that there were no leaking or blown cans in the sterility test. The three samples were significantly different in respect to appearance. The results showed the following order, from the least to the most acceptable sample: salt with onions, seasoned salt and edible oil. As for the global impression, the formulation in edible oil was also the most acceptable. The sodium chloride content was in the range of 0.5 to $1.2 \%$, where the highest value was found for the samples in salt. The canned meat

IPrograma de Pós-graduação em Higiene Veterinária e Processamento Tecnológico de Produtos de Origem Animal, Universidade Federal Fluminense (UFF), Niterói, RJ, Brasil.

IIPrograma de Pós-graduação em Ciência de Alimentos, Universidade Federal do Rio de Janeiro (UFRJ), Rio de Janeiro, RJ, Brasil. IIIDepartamento de Tecnologia dos Alimentos, UFF, Niterói, RJ, Brasil. 
samples had an average $p H$ of 5.0, $76.0 \%$ moisture content and $1.3 \%$ of fixed mineral residue, a protein concentration of $12.4 \%$ and a total lipid content of $5.5 \%$. The sample in edible oil showed a higher concentration of lipids (12.8\%). One can conclude from these results that it is possible to commercialize canned broad-snouted caiman meat, which allows a better use of the meat after the slaughter. There were also an increase in the value added and a good sensory acceptance of the product.

Key words: caiman meat, canned meat, acceptance test, percent composition.

\section{INTRODUÇÃo}

Nota-se no mercado brasileiro, o aumento do consumo de carnes provenientes não só da chamada fauna exótica, ou seja, daquelas espécies não presentes no país, mas também de carnes não convencionais (GIL, 2007). O projeto de criação em cativeiro é uma forma internacionalmente reconhecida como preservadora de espécies ameaçadas de extinção. O jacaré-do-papoamarelo (Caiman latirostris) se adapta bem ao cativeiro e ao semicativeiro, desde que atendidas, as suas exigências básicas como temperatura, umidade, higiene e nutrição (ARURÁ, 2007). De acordo com FETT (2005), o Brasil apresenta condições privilegiadas para o desenvolvimento e exploração sustentada de populações de crocodilianos existentes de forma natural no país. O autor ressalta que a criação de jacarés já é realizada por diversos criatórios aprovados pelo Instituto Brasileiro do Meio Ambiente e dos Recursos Naturais Renováveis (IBAMA). Em 1990, a Portaria n 126 do IBAMA (BRASIL, 1990) regulamentou a utilização do jacaré-do-pantanal em sistema semiextensivo de criação para fins comerciais, fazendo crescer a produção gradualmente.

De acordo com o artigo 378 do RIISPOA (Regulamento da Inspeção Industrial e Sanitária de Produtos de Origem Animal), entende-se por “conserva enlatada” todo produto em que a matéria-prima foi ou não curada, condimentada, embalada em recipiente metálico hermeticamente fechado, submetido a vácuo direto ou indireto e afinal, convenientemente, esterilizado pelo calor úmido e imediatamente esfriado, respeitada a peculiaridade do produto (BRASIL, 1952). ROMANELLI et al. (2002), em estudo sobre processamento da carne de jacaré-do-pantanal (Caiman crocodilus yacare), elaboraram carne em conserva, utilizando cubos de carne obtidos do corte do tronco, colocados em salmoura a 25\% durante 30 minutos, submetidos a branqueamento em vapor por 5 minutos, defumação por 40 minutos, acondicionamento em latas com adição de óleo de soja como líquido de cobertura, recravação e autoclavagem a $121^{\circ} \mathrm{C}$ durante
20 minutos. A aceitação sensorial foi realizada com as latas abertas para avaliação da aparência, cor e aroma, além do sabor, utilizando escala hedônica de sete pontos, variando entre os termos "gostei muitíssimo" e "desagradou-me muitíssimo”. O produto obteve um escore médio de 4,8 , que correspondeu a mais de $68 \%$ de aceitação, apesar de comentários negativos como “sem sabor” e "oleoso". Em relação ao aroma, foram mencionadas semelhanças ao atum em lata, e a aparência teve um alto grau de rejeição devido à presença de vestígios da membrana visceral aderente, de cor escura, além da presença de cubos de carne semelhantes ao toucinho suíno, de coloração mais clara.

A quantidade total de lipídios e a composição dos ácidos graxos na carne diferem, consideravelmente, entre as diferentes espécies animais (CHOW, 2000). MITCHELL et al. (1995) encontraram altos níveis dos ácidos graxos oléico (33,0\%), palmítico (22,5\%) e linoléico (15,2\%) na carne de Crocodylus porosus e Crocodylus johnstoni. PEPLOW et al. (1990) demonstraram a grande influência da dieta no perfil de ácidos graxos da carne do Alligator mississippiensis. Animais alimentados, com dietas à base de peixe, obtiveram uma concentração muito maior de ácidos graxos com cadeia de 20 carbonos ou mais, quando comparados aos animais alimentados com carne bovina. Os lipídeos dos crocodilos alimentados com dietas à base de peixe continham $11,1 \%$ de ácido docosahexaenóico e 4\% de ácido eicosapentaenóico, enquanto que os alimentados com carne bovina possuíam quantidades insignificantes desses ácidos graxos.

Visando ao melhor aproveitamento da carne de jacaré-do-papo-amarelo (Caiman latirostris), o aumento do seu valor agregado e a introdução de novos produtos no mercado, os objetivos neste trabalho foram avaliar três formulações de conservas: em óleo comestível, em salmoura com cebola e em salmoura temperada. Foram avaliadas a aceitação sensorial dos produtos em relação à aparência e impressão global, e a sua composição centesimal, incluindo análises de $\mathrm{pH}$, umidade, resíduo mineral fixo, proteínas, lipídeos, sódio e ácidos graxos.

\section{MATERIAL E MÉTODOS}

Após o abate, foram separados cortes não desossados, destinados à fabricação das conservas enlatadas, totalizando seis pares de membros (três pares de membros anteriores e três pares de posteriores), uma cauda, duas costelas e dois lombos. Esses cortes foram escolhidos com o objetivo de se avaliar a 
viabilidade do aproveitamento dos cortes de menor valor comercial para a fabricação do produto enlatado. Para isso, foi utilizada uma proporção maior de cortes menos nobres da carcaça, de desossa mais trabalhosa, como os membros, costelas e lombo.

A análise de ácidos graxos foi realizada somente na carne in natura, através de cromatografia em fase gasosa. Foram retirados fragmentos de todos os cortes (filé, lombo, coxa com sobrecoxa e costela), num total de $150 \mathrm{~g}$ de amostra, que foi homogeneizada em mixer e armazenada em freezer $\left(-18^{\circ} \mathrm{C}\right) \operatorname{com} \mathrm{BHT}(0,05 \%$; p/p) até o momento da análise. Os lipídios totais foram extraídos em duplicata com clorofórmio:metanol (2:1, v/v; FOLCH et al., 1957) em dispersor Ultra-Turrax ${ }^{\circledR}$ (IKA, Alemanha) e, em seguida, transesterificados, essencialmente como foi descrito por LEPAGE \& ROY (1986). Os ésteres metílicos resultantes foram analisados em cromatógrafo a gás GC-14B (Shimadzu, Japão), equipado com detector por ionização em chama e coluna capilar polar Omegawax ${ }^{\circledR}$ (Supelco, EUA). Durante as análises, o detector foi operado a $270^{\circ} \mathrm{C}$, o injetor foi operado a $260^{\circ} \mathrm{C}$, com divisão (1:20) do fluxo do gás de arraste (He) e o forno da coluna operado com o seguinte gradiente de temperatura: $140^{\circ} \mathrm{C}$ por $3 \mathrm{~min}$, seguido de elevação a $3,5^{\circ} \mathrm{C} \mathrm{min}^{-1}$ até $210^{\circ} \mathrm{C}$, que foi mantida por $30 \mathrm{~min}$. As análises qualitativas e quantitativas dos cromatogramas foram realizadas como descrito por TORRES et al. (2006).

Antes da desossa, a carne foi pré-cozida em calor úmido, à temperatura de $110^{\circ} \mathrm{C}$ e pressão de $0,5 \mathrm{Kgf} / \mathrm{cm}^{2}$ por 20 a 60 minutos. Em seguida, os cortes foram desossados e picados, manualmente, em pedaços bem pequenos, garantindo uma excelente mistura e homogeneização dos cortes diferentes em cada lata.

Para o preparo da conserva em salmoura temperada, foram misturados $1,7 \mathrm{~kg}$ de carne, $1 \mathrm{~kg}$ de cebola fatiada, $0,5 \mathrm{~kg}$ de pimentão e $0,6 \mathrm{~kg}$ de tomate picado. Para o preparo da conserva em salmoura com cebola, foram misturados $1,6 \mathrm{~kg}$ de carne e $1,5 \mathrm{~kg}$ de cebola fatiada. Para o preparo da conserva em óleo comestível, foi utilizada a carne picada e $2 \mathrm{~g}$ de sal refinado $(\mathrm{NaCl})$ por lata. Foi adicionado um total de $110 \mathrm{~g}$ de conteúdo em cada lata.

A salmoura foi preparada adicionando-se sal refinado $(\mathrm{NaCl})$ à água fervente, numa concentração de $3^{\circ}$ Beaumé. Adicionou-se a salmoura às amostras temperada e com cebola, num total de 1,5\% de salmoura em relação ao volume total da lata. O óleo de soja, previamente aquecido, foi adicionado à amostra em óleo, até o total preenchimento da lata.

As latas de folhas de Flandres, revestidas por verniz epóxi-fenólico, de formato circular e dimensões de 8,5cm de diâmetro por 4cm de altura foram levadas à máquina recravadeira, adicionando-se, manualmente o líquido de cobertura e, em seguida, autoclavadas, durante 45 minutos à temperatura de $116^{\circ} \mathrm{C}$ e pressão de $1,8 \mathrm{~kg} \mathrm{~cm}^{-2}$. Essas condições são as mesmas utilizadas para o enlatamento do atum, já que não existe um procedimento padrão para a carne de jacaré(BRASIL, 1952).

Antes de dar início à análise sensorial, foi realizado o teste de esterilidade comercial para alimentos de baixa acidez $(\mathrm{pH}=4,6)$ de acordo com os procedimentos descritos, no capítulo XX, da Instrução Normativa 62, do Ministério da Agricultura, Pecuária e Abastecimento (BRASIL, 2003). O objetivo do teste foi verificar-se a eficácia do processo de esterilização, aplicado a alimentos de baixa acidez, comercialmente estéreis (enlatados).

Após o término do teste de esterilidade, deu-se início à avaliação sensorial do produto, na qual se empregou o teste de aceitação com escala hedônica estruturada de nove pontos. Avaliou-se a aparência do produto na lata aberta e, após a degustação, a impressão global das três formulações. Os testes foram realizados por 100 consumidores não treinados, em cabines individuais, sob condições laboratoriais. As amostras foram codificadas com números de três dígitos, apresentadas de forma monádica, em ordem aleatória, servidas em pratos de cor clara, com um copo contendo água para o enxágüe bucal e ficha de avaliação. O objetivo do teste não foi a comparação entre as amostras, mas sim a verificação do grau de aceitação de cada amostra individualmente. Por isso, as amostras não foram servidas juntas, mas de forma monádica, com uma ficha de avaliação para cada amostra e não uma ficha única para que o consumidor marcasse a amostra preferida dentre as três. Como era um alimento elaborado especificamente para pesquisa, não disponível comercialmente, os consumidores não possuíam memória sensorial anterior para realizar comparações. Ao final do teste, a média de aceitação de cada amostra foi comparada com as demais, para avaliar qual apresentou maior grau de aceitação.

A análise de sódio foi realizada de acordo com as Normas Analíticas do INSTITUTO ADOLFO LUTZ (1985), que consiste em determinar o resíduo mineral fixo da amostra, adicionar uma solução de ácido nítrico, neutralizar com carbonato de cálcio e titular com solução de nitrato de prata, utilizando solução de cromato de potássio como indicador.

Para a análise de $\mathrm{pH}$, foi utilizado o método potenciométrico, de acordo com o método descrito no LANARA (BRASIL, 1981) para a carne bovina in natura. As análises de umidade foram realizadas de 
acordo com o método da secagem em estufa a $105^{\circ} \mathrm{C}$ de acordo com LANARA (BRASIL, 1981). O resíduo mineral fixo foi obtido, segundo o método da incineração em mufla (BRASIL, 1981), após a carbonização da matéria orgânica em bico de Bunsen. A análise de lipídeos foi realizada de conforme o método de Soxhlet (BRASIL, 1981), utilizando o éter de petróleo como solvente. A análise de proteínas foi realizada de acordo com o método de Micro Kjeldahl (BRASIL, 1981), que consiste nas etapas de digestão, destilação e titulação.

A análise estatística foi realizada pela análise de variância por meio do procedimento "General Analytical Models" do pacote estatístico "Statistical Analytical System” (SAS INSTITUTE, 1999). Para comparação entre as médias, foi utilizado o teste de Tukey, em nível de 5\% de significância.

\section{RESULTADOS E DISCUSSÃO}

No teste de esterilidade comercial, as latas não apresentaram indícios de vazamento devido à perfuração ou defeito na recravação. Também não ocorreu o estufamento das latas, sendo liberadas para a avaliação sensorial.

Dos 100 consumidores que participaram das análises sensoriais, 61 eram mulheres e 39 homens, na faixa etária de 17 a 69 anos. Desses, somente seis homens e seis mulheres (12\% do total) já haviam experimentado carne de jacaré.

Em relação à aparência, as três amostras diferiram significativamente (ANOVA; $\mathrm{P}<0,05$ ) entre si, sendo a conserva em cebola a menos aceita, seguida da amostra temperada e em óleo, que foi a mais aceita, ficando próxima ao termo hedônico "gostei moderadamente”. Os escores médios variaram de 5,1 (amostra com cebola) a 6,8 (amostra em óleo). Em relação à impressão global, a amostra em óleo também foi a melhor aceita (termo hedônico "gostei moderadamente”, escore médio de 7,2), gerando alguns comentários positivos em relação ao sabor, como "sabor agradável/saborosa” e "sabor suave”, e à textura como "textura boa” e "suculenta”. A conserva em salmoura com cebola e a temperada não diferiram significativamente entre si (termo hedônico "gostei ligeiramente”, com escores médios de 6,3 e 6,5, respectivamente), gerando alguns comentários negativos do tipo "os temperos mascaram o sabor da carne”, “não gosto de cebola/pimentão”.

ROMANELLI et al. (2002) elaboraram conservas a partir da carne de jacaré-do-pantanal (Caiman crocodilus yacare), empregando-se defumação e posterior enlatamento, obtendo uma aceitação regular (mais de 68\%), que ficou entre os termos hedônicos "gostei ligeiramente" e "gostei moderadamente”, resultado equivalente ao encontrado no presente estudo.

$\mathrm{Na}$ análise de ácidos graxos da carne in natura, observou-se que o ácido graxo mais abundante na carne do jacaré foi o monoinsaturado octadecenóico (oléico, 18:1 n-9), seguido pelo poliinsaturado octadecadienóico (linoléico, 18:2 n-6) e pelo saturado hexadecanóico (palmítico, 16:0). Os ácidos graxos saturados corresponderam a 28,5\% do total de ácidos graxos, os monoinsaturados corresponderam a $42,5 \%$ do total e os poliinsaturados a $29,0 \%$ do total. Destacouse a elevada concentração do ácido graxo essencial linoléico (18:2 n-6), além da presença do alfa e gama linolênico em menor concentração. Os ácidos graxos da série ômega 6 corresponderam a 27,4\% do total e os da série ômega 3 corresponderam a 1,55\%. Esses resultados diferiram dos obtidos por HOFFMAN et al. (2000), que estudaram o perfil de ácidos graxos da carne da cauda do Crocodylus niloticus, encontrando um total de 37,7\% de ácidos graxos saturados, 51,1\% de monoinsaturados e $10,7 \%$ de poliinsaturados, sendo 1,69\% de ômega 3 e 9,05\% de ômega 6.

Os resultados obtidos por MITCHELL et al. (1995), na carne de Crocodylus porosus e Crocodylus johnstoni, assemelham-se aos do presente estudo, em que o ácido graxo oléico foi o encontrado em maior concentração, seguido pelo linoléico e palmítico, com concentrações mais próximas. Esses autores encontraram 3,60\% de ácido araquidônico, semelhante ao resultado obtido nesta análise. Eles encontraram um total de 8,3\% ômega 3 e 19,2\% de ômega 6 .

A influência da dieta observada por PEPLOW et al. (1990), no perfil de ácidos graxos da carne do Alligator mississippiensis está de acordo com os resultados obtidos nesta análise, visto que a dieta dos jacarés do presente estudo não incluiu peixes, mas apenas frangos, coelhos e suínos, e a concentração obtida de ácido docosahexaenóico foi baixa (0,52\%) e não foi encontrado o ácido eicosapentaenóico. Eses autores também encontraram em maior concentração, os ácidos graxos oléico e palmítico.

As diferenças, nas concentrações de ácidos graxos encontradas em diferentes estudos, podem ser explicadas por se tratar de espécies diferentes, alimentadas com dietas diferentes, que influenciam a composição dos ácidos graxos encontrados na carne. Além disso, a composição de ácidos graxos também pode variar de acordo com o corte analisado.

As conservas apresentaram uma média de $0,85 \%$ de cloreto de sódio, variando de $0,52 \%$, na conserva em óleo, a 1,25\%, na conserva em salmoura, temperada. 
As conservas, com adição de salmoura, apresentaram um teor mais elevado de cloreto de sódio. Considerando-se que foi adicionado $2 \mathrm{~g}$ de sal refinado na conserva em óleo, e salmoura a $3^{\circ} \mathrm{Be}$ (cerca de 3,5\% de cloreto de sódio) nas demais conservas, sendo que uma lata possui um conteúdo total de $180 \mathrm{~g}$, a concentração obtida encontrase dentro do esperado, já que durante o preparo da amostra, para obtenção do resíduo mineral fixo, foi removido o excesso do líquido de cobertura, para simular o preparo doméstico do produto.

Os resultados das análises da composição centesimal e do $\mathrm{pH}$ estão dispostos na tabela 1. Os valores de $\mathrm{pH}$ encontrados para as conservas estão de acordo com o pH definido pela Instrução Normativa 62 do Ministério da Agricultura, Pecuária e Abastecimento (BRASIL, 2003) para alimentos comercialmente estéreis de baixa acidez (enlatados), que define um $\mathrm{pH}=4,6$.

De acordo com a Tabela Brasileira de Composição de Alimentos (NEPA, 2006), a conserva em óleo apresentou um teor de umidade bem semelhante ao do atum fresco. O seu menor teor de umidade foi acompanhado pelo maior teor de lipídeos, bem mais alto que o das outras conservas, já que o óleo de soja é composto basicamente por lipídeos. Seu resíduo mineral fixo foi semelhante à sardinha crua, teor protéico semelhante à sardinha em óleo e teor de lipídeos semelhante ao pernil suíno (NEPA, 2006).

A conserva em cebola apresentou umidade semelhante à coxa e peito de frango, resíduo mineral fixo com teor semelhante a várias espécies (bovina, frango e suína), o menor teor de proteínas, se comparada às demais conservas, ficando mais próxima à sardinha em conserva, porém ainda apresentando um teor consideravelmente menor que esta. Seu teor de lipídeos ficou mais próximo ao do peru e da sardinha crua (NEPA, 2006).

A conserva temperada apresentou um teor de umidade semelhante ao da sardinha crua e à coxa e peito de frango. Conforme a Tabela Brasileira de Composição de Alimentos (NEPA, 2006), a cebola, o tomate e o pimentão possuem um teor de umidade bastante elevado e, conseqüentemente, a conserva temperada foi a que apresentou o maior teor de umidade, se comparada às demais conservas. Apresentou o resíduo mineral fixo bastante semelhante ao do atum cru. Seu teor protéico aproximou-se mais ao da sardinha em conserva, e seu teor de lipídeos foi o mais baixo, se comparado às demais conservas, ficando próximo ao atum e ao peru crus.

Os carboidratos, dentre os quais se inclui a fibra alimentar, presentes no tomate, cebola e pimentão, contribuíram para gerar o menor teor protéico das conservas em cebola e temperada, visto que a presença dos demais ingredientes de origem vegetal, bastante pobres em proteínas, acabou reduzindo o teor protéico total dessas conservas.

\section{CONCLUSÃO}

A fabricação de carne de jacaré-do-papoamarelo em conserva é viável, pois permite um melhor aproveitamento da carne após o abate, agregando valor ao produto final. A boa aceitação observada na análise sensorial, confirma a viabilidade da comercialização desse tipo de produto. A conserva em óleo comestível foi a mais aceita, sendo a indicada para comercialização.

A carne de jacaré-do-papo-amarelo in natura é um alimento de elevado valor nutritivo, destacando-se a elevada concentração do ácido graxo essencial linoléico, além da presença do alfa e gama linolênico, num total de 27,4\% de ácidos graxos da série ômega 6 e 1,55\% da série ômega 3. A composição centesimal das conservas variou em função da adição de outros ingredientes, porém destaca-se seu elevado teor protéico.

\section{COMITÊ DE ÉTICA E BIOSSEGURANÇA}

A utilização dos animais nesta pesquisa foi aprovada pelo Comitê de Ética e Biossegurança da Universidade Federal Fluminense, visto que os animais eram oriundos de estabelecimento registrado no IBAMA e foram utilizados métodos humanitários de abate.

Tabela 1 - Valores médios de três repetições das análises físico-químicas das conservas de carne de jacaré-do-papo-amarelo (Caiman latirostris).

\begin{tabular}{lccc}
\hline Análise & Conserva em óleo & Conserva com cebola & Conserva temperada \\
\hline $\mathrm{pH}$ & 5,3 & 4,9 & 4,8 \\
Umidade (\%) & 73,9 & 76,2 & 78,0 \\
Resíduo mineral fixo (\%) & 1,8 & 0,9 & 1,3 \\
Proteínas (\%) & 14,5 & 10,0 & 12,7 \\
Lipídeos (\%) & 12,8 & 2,4 & 1,4 \\
\hline
\end{tabular}




\section{REFERÊNCIAS}

ARURÁ. Criadouro Conservacionista de lobo-guará e Comercial de jacaré-do-papo-amarelo. Capturado em 14 fev. 2007. Online. Disponível em: <http://www.arura.com.br/>.

BRASIL. Ministério da Agricultura, Pecuária e Abastecimento. Secretaria de Defesa Agropecuária. Departamento de Inspeção de Produtos de Origem Animal. Regulamento da Inspeção Industrial e Sanitária de Produtos de Origem Animal (RIISPOA). Aprovado pelo Decreto nํ. 30.691, 29/03/52, alterado pelos Decretos no 1255 de 25/06/62, 1236 de 02/09/ 94, 1812 de 08/02/96 e 2244 de 04/06/97. Brasília, 1952. 241p.

BRASIL. Ministério da Agricultura, Pecuária e Abastecimento. Secretaria Nacional de Defesa Agropecuária. Laboratório Nacional de Referência Animal (LANARA). Métodos analíticos oficiais para controle de produtos de origem animal e seus ingredientes. II. Métodos Físico Químicos. Brasília, 1981. 123p.

BRASIL. Ministério da Agricultura, Pecuária e Abastecimento. Instrução normativa $n^{\circ}$ 62, de 26 de agosto de 2003. Oficializa os Métodos Analíticos Oficiais para Análises Microbiológicas para Controle de Produtos de Origem Animal e Água. Diário Oficial da União, Brasília, p.14, 18 set. 2003. Seção 1.

BRASIL. Ministério do Meio Ambiente. Instituto Brasileiro do Meio Ambiente e dos Recursos Naturais Renováveis. Portaria no 126 , de 13 de fevereiro de 1990. Legislação Ambiental Brasileira. Diário Oficial da União, Brasília, n.035, p.3.3323.333, 19 fev. 1990. Seção 1.

CHOW, C.K. Fatty acids in foods and their health implications. 2.ed. USA: Marcel Dekker, 2000. 1045p.

FETT, M.S. Serviço Brasileiro de Respostas Técnicas SENAI, RS, 29 set. 2005. Capturado em 13 mar. 2006. Online. Disponível em: <http://sbrt.ibict.br/upload/sbrt1435.pdf>.

FOLCH, J. et al. A simple method for the isolation and purification of total lipids from animal tissues. Journal of Biological Chemistry, v.226, p.497-509, 1957.
GIL, A. Carnes exóticas. Superintendência do IBAMA no Rio de Janeiro (SUPES), 2007. Capturado em 14 nov. 2006. Online. Disponível em: <http://www.ibama.gov.br/rj/ index.php?id_menu=228>.

HOFFMAN, L.C. et al. Carcass and meat characteristics of the Nile crocodile (Crocodylus niloticus). Journal of the Science of Food and Agriculture, v.80, p.390-396, 2000.

INSTITUTO ADOLFO LUTZ. Normas Analíticas do Instituto Adolfo Lutz: Métodos químicos e físicos para análise de alimentos. 3.ed. São Paulo, 1985. V.1, 533p.

LEPAGE, G.; ROY, C.C. Direct transesterification of all classes of lipids in a one-step reaction. Journal of Lipid Research, v.27, p.114-120, 1986.

MITCHELL, G.E. et al. Composition of crocodile meat (Crocodylus porosus and Crocodylus johnstoni). Food Australia, v.47, p.221-224, 1995.

NEPA (Núcleo de Estudos e Pesquisas em Alimentação). Tabela Brasileira de Composição de Alimentos (TACO). Universidade Estadual de Campinas, 2006. Capturado em 27 set. 2006. Online. Disponível em: <http://www.unicamp.br/ nepa/taco/contar/taco_versao2.pdf $>$.

PEPLOW, A. et al. Lipid composition of fat trimmings from farm raised alligator. Aquaculture, v.91, p.339-348, 1990.

ROMANELLI, P.F. et al. Processamento da carne do jacaré do Pantanal (Caiman crocodylus yacare). Ciência e Tecnologia de Alimentos, v.22, n.01, p.70-75, 2002.

SAS INSTITUTE. SAS user's guide. 6.04 Edition. Cary, NC., 1999 . 956p.

TORRES, A.G. et al. Polyunsaturated fatty acids and conjugated linoleic acid isomers in breast milk are associated with plasma non-esterified and erythrocyte membrane fatty acid composition in lactating women. British Journal of Nutrition, v.95, n.03, p.517-524, 2006. 